\title{
Determination and distribution of polycyclic aromatic hydrocarbons in rivers, surface runoff, and sediments in and around Thohoyandou, Limpopo Province, South Africa
}

\author{
Takalani Joyce Nekhavhambe ${ }^{1}$, Teunis van Ree ${ }^{1 *}$ and Olalekan Siyanbola Fatoki \\ 'Department of Chemistry, University of Venda, Private Bag X5050, Thohoyandou 0950, South Africa \\ ${ }^{2}$ Faculty of Applied Sciences, Cape Peninsula University of Technology, PO Box 1906, Bellville 7535, South Africa
}

\begin{abstract}
Water quality in rural areas is affected adversely by build-up of traffic-generated organic compounds on road surfaces, leading to their presence in water runoff and sediments. Characterising these compounds is a first step in developing measures for the removal of such pollutants from water courses. In this study, liquid-liquid extraction of water samples from several rivers and surface run-off enabled quantification of major PAHs. Soxhlet extraction of sediment samples was followed by clean-up of samples using column chromatography. The PAHs were quantified by gas chromatography. In water and sediment samples, 6 PAHs were identified and quantified. In river water samples, individual PAH levels ranged between $0.1 \mu \mathrm{g} / \ell$ and $137 \mu \mathrm{g} / \ell$, while in sediment samples levels ranged between $17.9 \mu \mathrm{g} / \mathrm{kg}$ and $9870 \mu \mathrm{g} / \mathrm{kg}$. For surface run-off, levels ranged between $0.6 \mu \mathrm{g} / \ell$ and $2500 \mu \mathrm{g} / \ell$ for water samples and between $112 \mu \mathrm{g} / \mathrm{kg}$ and $34400 \mu \mathrm{g} / \mathrm{kg}$ for sediment samples. Total levels of PAHs in sediment samples were relatively high (111.6 to $61764 \mu \mathrm{g} / \mathrm{kg}$ ) compared to those in water from both river and surface run-off (29.2 to $3064.8 \mu \mathrm{g} / \ell$ ), and PAH levels in surface runoff were much higher than in river waters, implicating tarred roads and parking lots as main point sources of PAHs. PAH ratios also indicate that the PAH content of runoff and sediment is more likely due to pyrogenic sources, i.e. vehicle emissions, although petrogenic sources (mainly oil spills) also play an important role. Toxic Equivalence Quotient (TEQ) values in river and runoff waters ranged from 0.10 to $4.03 \mu \mathrm{g} / \ell$ and for sediments the TEQ ranged from 0.50 to $272.23 \mu \mathrm{g} / \mathrm{kg}$. These results are of concern, as the calculated TEQ is likely to be an underestimate of the actual TEQ, since only 6 PAHs with relatively low toxicities were analysed. Long droughts and low rainfall, and washing of automobiles in and near the rivers are important factors which may have contributed to the observed levels of PAHs in both river water and sediments.
\end{abstract}

Keywords: Polycyclic aromatic hydrocarbon, river water, runoff, sediment

\section{INTRODUCTION}

The toxicity of polycyclic aromatic hydrocarbons (PAHs) and their widespread distribution has led to more interest in the presence of these compounds in the aquatic and terrestrial environment. Many studies have been done in developed countries (e.g., Crystal and Foster, 1991; Maldonado et al., 1999), but in South Africa few studies have been conducted to determine the presence and levels of PAHs in the environment (Butler and Sibbald, 1986). Das et al. (2008) followed the sources of, and historic changes in, PAH inputs to Zeekoevlei since the early 1990s, and found very low levels of low molecular weight (MW) PAHs, attributable to low traffic volumes in the catchment, with higher concentrations of high-MW PAHs during the rainy winter season, suggesting stormwater input and atmospheric deposition from non-point sources. Nieuwoudt et al. (2011) extensively investigated soils and sediments collected from central South Africa, specifically targeting industrial, residential, and agricultural areas. The total concentration of PAHs was found to range between 44 and $39000 \mathrm{ng} / \mathrm{g}$ with pyrogenic processes the most likely sources. PAH levels were in the same range as levels reported from other countries.

To whom all correspondence should be addressed.

Iif +27 15 962-8262; fax: +27 15 962-4749;

e-mail: Teuns.VanRee@univen.ac.za

Received 9 May 2013; accepted in revised form 6 May 2014.
The Limpopo Province of South Africa has a number of rivers receiving PAHs from rainfall runoff from parking lots, tarred roads, brickyards, formal and backyard incineration areas and scrap yards. For example, in the Thohoyandou area, at least 20 scrap yards can be found (looking4spares, 2014). This study was aimed mainly at investigating the state of sediments, water quality and surface runoff of selected rivers in Limpopo Province with respect to the levels of PAHs, focusing on 6 PAHs, viz. pyrene, azulene (used in dyes, cosmetics and lightemitting diodes), indene (produced by pyrolysis of higher boiling petroleum fractions), anthracene, dibenzothiophene, and fluoranthene. These PAHs were considered representative of PAHs occurring generally in water, sediments and surface runoff in rivers of the Thohoyandou area. Although not generally considered with other PAHs, dibenzothiophene was included as a water-soluble marker for heavier oil fractions (Wang and Fingas, 1995; Zeng et al., 2004) and persistent in older petroleum residues (Sauer and Boehm, 1991; Passivirta, 1991).

The scarcity of water resources in South Africa, combined with limited health budgets, pollution by different industries and lack of proper waste management, call for improved measures to manage the release of PAHs into the environment. The fact that few studies have been conducted in South Africa makes this study unique and important. Exposure of humans and wildlife to PAHs occurs via different pathways, such as inhalation, consumption and skin contact (Deutsch-Wenzel et al., 1983; Crystal and Foster, 1991). The present study was conducted in water because water forms an important component 

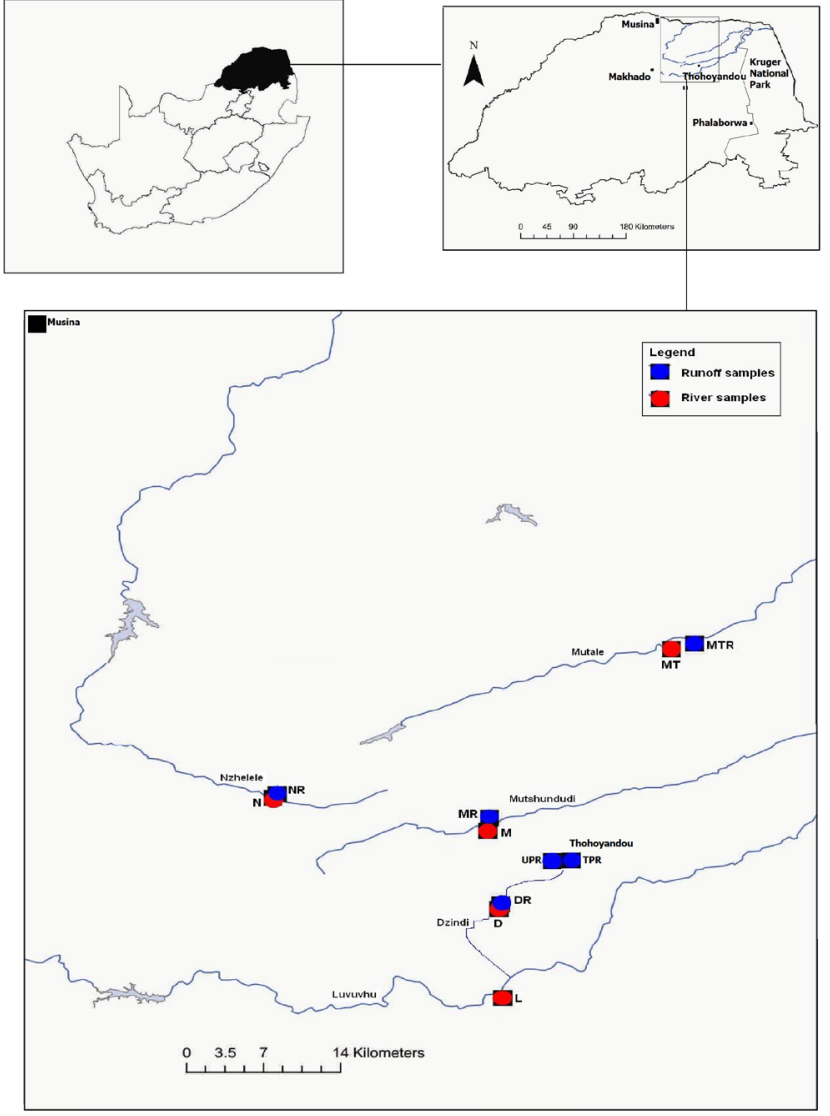

Figure 1

Location of the study area. Sampling points are described in Table 1 of different routes of contamination. Surface run-off represents a wide range of pollutants, and sediment acts as sink of PAHs because of their low solubility (Ogunfowokan et al., 2003). Road traffic parameters such as average daily traffic and surface texture depth can also significantly influence organic pollutant build-up (Mahbub et al., 2010). It is hoped that this study will provide a background for mitigating the impacts of PAHs transported by stormwater runoff to receiving waters.

\section{METHODS}

\section{Study area}

The study area for this research was the Vhembe District in the Limpopo Province of South Africa (Fig. 1). The province shares borders with the neighbouring SADC (Southern African Development Community) countries Zimbabwe and Mozambique. Important towns in this province are Thohoyandou, Makhado, Thabazimbi, Polokwane, Lephalale and Musina. Thohoyandou is the largest town in the district. The underdeveloped rural regions of the Limpopo Province are subject to periodic droughts and environmental degeneration because of poor water supply and infrastructure. Despite recent improvements, rural people still use water directly from streams for household purposes, which include washing of laundry and car washing and bathing directly in the river. The Mutshundudi, Mutale and Dzindi Rivers originate on the southern slopes of the Soutpansberg mountain range and are tributaries of the Luvuvhu River, which flows through the Kruger National Park (KNP) to join the Limpopo River. The Nzhelele River is the only perennial river in the study area, located on the northern slopes of the Soutpansberg and flowing into the Limpopo River (Angliss et al., 2001). Agricultural activity in the catchment consists of commercial pine, alien mahogany and eucalyptus plantations, while tea, mangoes, bananas, macadamia nuts and citrus are produced by commercial and subsistence farmers (Angliss et al. 2001).

\begin{tabular}{|c|c|c|c|}
\hline \multicolumn{4}{|c|}{$\begin{array}{c}\text { TABLE } 1 \\
\text { Description of sampling points } \\
\end{array}$} \\
\hline Code & Short description (Table 2) & Map reference & Full description \\
\hline $\mathrm{N}$ & Nzhelele River water and sediment & $\begin{array}{l}\text { S } 22^{\circ} 54.934^{\prime} \\
\text { E } 30^{\circ} 12.814^{\prime} \\
\end{array}$ & Nzhelele River under Dopeni bridge \\
\hline M & Mutshundudi River water and sediment & $\begin{array}{l}\text { S } 22^{\circ} 56.837^{\prime} \\
\text { E } 30^{\circ} 23.353^{\prime} \\
\end{array}$ & Mutshundudi River above Phiphidi waterfall \\
\hline MT & Mutale River water and sediment & $\begin{array}{l}\text { S } 22^{\circ} 46.377^{\prime} \\
\text { E } 30^{\circ} 32.356^{\prime} \\
\end{array}$ & Mutale River under Mutale bridge \\
\hline $\mathrm{D}$ & Dzindi River water and sediment & $\begin{array}{l}\text { S } 23^{\circ} 01.315^{\prime} \\
\text { E } 30^{\circ} 23.906^{\prime} \\
\end{array}$ & Dzindi River under Dzindi bridge \\
\hline $\mathrm{L}$ & Luvuvhu River water and sediment & $\begin{array}{l}\text { S 2306.415' } \\
\text { E 30⒉092' }\end{array}$ & Luvuvhu River near Tshino \\
\hline NR & Nzhelele Road runoff and sediment & $\begin{array}{l}\text { S } 22^{\circ} 54.699^{\prime} \\
\text { E } 30^{\circ} 13.032^{\prime}\end{array}$ & Tshikombani taxi rank, near Dopeni bridge \\
\hline MR & Mutshundudi Road runoff and sediment & $\begin{array}{l}\text { S } 22^{\circ} 56.095^{\prime} \\
\text { E } 30^{\circ} 23.434^{\prime}\end{array}$ & Mutshundudi road, near Phiphidi purification plant \\
\hline MTR & Mutale Road runoff and sediment & $\begin{array}{l}\text { S } 22^{\circ} 46.056^{\prime} \\
\text { E } 30^{\circ} 33.496^{\prime} \\
\end{array}$ & Mutale Road, at Shadani \\
\hline DR & Dzindi Road runoff and sediment & $\begin{array}{l}\text { S } 23^{\circ} 01.022^{\prime} \\
\text { E } 30^{\circ} 23.981^{\prime} \\
\end{array}$ & Tshisaulu Road near Dzindi Dam \\
\hline TP & Thohoyandou Parking runoff and sediment & $\begin{array}{l}\text { S } 22^{\circ} 58.546^{\prime} \\
\text { E } 30^{\circ} 27.431^{\prime} \\
\end{array}$ & Thohoyandou Shell Garage \\
\hline UP & Univen Parking runoff and sediment & $\begin{array}{l}\text { S } 22^{\circ} 58.566^{\prime} \\
\text { E } 30^{\circ} 26.517^{\prime}\end{array}$ & Univen Library Parking lot \\
\hline
\end{tabular}




\section{Chemicals}

Merck silica gel (particle size $0.040-0.063 \mathrm{~mm}$ ) was used for column chromatography. Dichloromethane and n-hexane $99.5 \%$ were obtained from Aldrich; solvents were double distilled to remove impurities. Reagent grade sodium chloride, anhydrous sodium sulphate and sodium carbonate and analytical grade anthracene, azulene, dibenzothiophene, fluoranthene, indene, and pyrene were supplied by Aldrich.

\section{Sampling}

Thirty-eight (38) samples were collected during 6 sampling cycles and analysed (19 sediment samples and 19 water samples). Samples were collected during the rainy season, usually a day after significant rainfall (September 2005 to January 2006). The river water and sediment sampling points for this study were: Nzhelele River, Luvuvhu River, Mutale River, Mutshundudi River and Dzindi River, while runoff water and sediments were sampled near these sites where roads crossed these rivers (4 sites), and on 2 parking lots (Fig. 1; Table 1). Water and sediment samples were collected 3 different times (if possible) from the different sampling sites (Table 2) over a period of 5 months during the rainy season.

Water run-off samples were collected at riverbanks at points where run-off enters these rivers, and on roadsides and parking lots around Thohoyandou Town as shown in Table 1. Water samples were collected in the water column $30 \mathrm{~cm}$ above the riverbed of the selected rivers, while sediment samples were taken with a sampling spear, which was inserted to a depth of up to 30 $\mathrm{cm}$ in the river bed. Three different sediment samples were taken at three different spots in the sampling area, which were then combined to give one representative sample. Three aliquots of water samples were taken and combined together into $2.5 \ell$ bottles with a screw cap lined with aluminium foil. Run-off sediment samples were also collected from rainwater, and sample spears were used to collect sediment samples. Run-off samples were taken at points where run-off enters these rivers, at roadsides and at parking lots.

Sediment samples were collected from the same locations as water samples. Water samples were stored at $<4^{\circ} \mathrm{C}$ and were analysed as soon as possible after collection.

Wet sediment samples were collected in clean glass bottles. Run-off water samples, i.e., rainwater runoff, collected after a rainfall event, were collected as described above for water samples. Samples were kept cool during transportation, and in the laboratory were kept frozen awaiting sample preparation and analysis. Sediment samples were air-dried for 3 days and sieved with $0.5 \mathrm{~mm}$ mesh sieves (Ogunfowokan et al., 2003).

\section{Extraction}

Liquid-liquid extraction was used for the extraction of river water and surface runoff in this study, using the methods of Rezaee et al. (2006) and El-Beqqali et al. (2006). A $500 \mathrm{~m} \ell$ aliquot was saturated with $75 \mathrm{~g} \mathrm{NaCl}$, transferred to a separating funnel and extracted 3 times by shaking vigorously with $30 \mathrm{~m} \ell$ dichloromethane. The 3 extracts were combined and washed 3 times with $30 \mathrm{m \ell} 0.1 \mathrm{M}$ sodium carbonate in a $100 \mathrm{~m} \ell$ separating funnel. The organic layer was separated and dried with anhydrous $\mathrm{Na}_{2} \mathrm{SO}_{4}$. The dried extract was reduced by evaporation and re-dissolved in $1 \mathrm{~m} \ell n$-hexane.

TABLE 2

Sampling summary. Sample number: (R)W or (R)S after the area code refers to (runoff) water or (runoff) sediment. Final digit indicates sampling cycle.

\begin{tabular}{|c|c|c|c|}
\hline \begin{tabular}{|l|} 
Sample \\
Number
\end{tabular} & Material & Sample Date & Sampling Point \\
\hline MW1 & Water & $09 / 08 / 2005$ & Mutshundudi River \\
\hline MS1 & Sediment & $09 / 08 / 2005$ & Mutshundudi River \\
\hline MW2 & Water & $27 / 08 / 2005$ & Mutshundudi River \\
\hline MS2 & Sediment & $27 / 08 / 2005$ & Mutshundudi River \\
\hline MW3 & Water & $23 / 09 / 2005$ & Mutshundudi River \\
\hline MS3 & Sediment & $23 / 09 / 2005$ & Mutshundudi River \\
\hline NW1 & Water & $09 / 08 / 2005$ & Nzhelele River \\
\hline NS1 & Sediment & $09 / 08 / 2005$ & Nzhelele River \\
\hline NW2 & Water & $27 / 08 / 2005$ & Nzhelele River \\
\hline NS2 & Sediment & $27 / 08 / 2005$ & Nzhelele River \\
\hline NW3 & Water & $23 / 09 / 2005$ & Nzhelele River \\
\hline NS3 & Sediment & $23 / 09 / 2005$ & Nzhelele River \\
\hline MTW2 & Water & $27 / 08 / 2005$ & Mutale River \\
\hline MTS2 & Sediment & $27 / 08 / 2005$ & Mutale River \\
\hline DW3 & Water & $24 / 09 / 2005$ & Dzindi River \\
\hline DS3 & Sediment & $24 / 09 / 2005$ & Dzindi River \\
\hline LW3 & Water & $24 / 09 / 2005$ & Luvuvhu River \\
\hline LS3 & Sediment & $24 / 09 / 2005$ & Luvuvhu River \\
\hline MTRW4 & Runoff water & $01 / 12 / 2005$ & Mutale Road \\
\hline MTRS4 & Runoff sediment & $01 / 12 / 2005$ & Mutale Road \\
\hline TPRW4 & Runoff water & $01 / 12 / 2005$ & Thohoyandou Parking \\
\hline TPRS4 & Runoff sediment & $01 / 12 / 2005$ & Thohoyandou Parking \\
\hline TPRW5 & Runoff water & $19 / 12 / 2005$ & Thohoyandou Parking \\
\hline TPRS5 & Runoff sediment & $19 / 12 / 2005$ & Thohoyandou Parking \\
\hline UPRW5 & Runoff water & $19 / 12 / 2005$ & Univen Parking \\
\hline UPRS5 & Runoff sediment & $19 / 12 / 2005$ & Univen Parking \\
\hline MRW5 & Runoff water & $21 / 12 / 2005$ & Mutshundudi Road \\
\hline MRS5 & Runoff sediment & $10 / 01 / 2006$ & Mutshundudi Road \\
\hline MRW6 & Runoff water & $10 / 01 / 2006$ & Mutshundudi Road \\
\hline MRS6 & Runoff sediment & $10 / 01 / 2006$ & Mutshundudi Road \\
\hline MTRW5 & Runoff water & $21 / 12 / 2005$ & Mutale Road \\
\hline MTRS5 & Runoff sediment & $21 / 12 / 2005$ & Mutale Road \\
\hline NRW5 & Runoff water & $21 / 12 / 2005$ & Nzhelele Road \\
\hline NRS5 & Runoff sediment & $21 / 12 / 2005$ & Nzhelele Road \\
\hline NRW6 & Runoff water & $10 / 01 / 2006$ & Nzhelele Road \\
\hline NRS6 & Runoff sediment & $10 / 01 / 2006$ & Nzhelele Road \\
\hline DRW6 & Runoff water & $10 / 01 / 2006$ & Dzindi Road \\
\hline DRS6 & Runoff sediment & $10 / 01 / 2006$ & Dzindi Road \\
\hline
\end{tabular}


Soxhlet extraction was used for the extraction of sediment samples (US EPA, 1996) for the extraction of semi-volatile and non-volatile organics from solid matrices. Sediment samples were air dried, crushed with mortar and pestle and sieved through a $0.5 \mathrm{~mm}$ mesh sieve. Ten grams of sediment sample were weighed into an extraction thimble, which had been pre-extracted with dichloromethane, placed in a Soxhlet extractor and extracted with $30 \mathrm{~m} \ell$ of dichloromethane for $12 \mathrm{~h}$. The extract was then reduced to about $10 \mathrm{ml}$ on a water bath at $38^{\circ} \mathrm{C}$ with the condenser water cooled to $4^{\circ} \mathrm{C}$. The reduced extract was transferred to a $100 \mathrm{~m} \ell$ separating funnel and $20 \mathrm{~m} \ell$ distilled water added to the extract. The mixture was washed with three $10 \mathrm{~m} \ell$ portions $0.1 \mathrm{M}$ sodium carbonate. The extraction was done in triplicate. The dried extract was reduced by evaporation and re-dissolved in $1 \mathrm{ml}$ $n$-hexane.

\section{Validation}

Low extraction efficiencies of PAHs have been demonstrated and additional losses of PAHs can also occur during purification and concentration of extracts before analysis, which may lead to underestimation (Ghiasvand et al., 2006). Validation studies were therefore carried out in terms of recovery of PAHs to show that the extraction procedures for both sediment and water were efficient. This was done by adding $1 \mathrm{~m} \ell$ of 1000 $\mathrm{mg} / \ell$ standard mixture consisting of 6 PAHs to $500 \mathrm{~m} \ell$ preextracted water samples. Double-distilled water $(500 \mathrm{~m} \ell)$ was first pre-extracted in triplicate with $30 \mathrm{~m} \ell$ dichloromethane as a blank sample.

Sediment samples were also spiked for validation purposes. Spiked dried pre-extracted sediment samples (10 g each) were extracted with $30 \mathrm{~m} \ell$ dichloromethane each. To the preextracted sediment samples $1.0 \mathrm{~m} \ell$ of $10 \mathrm{mg} / \ell \mathrm{PAH}$ standard mixture was added, after which the samples were air-dried. The spiked water and sediment samples were then extracted and analysed.

Absolute calibration was carried out by measuring peak areas obtained from known amounts of standard solutions. The resulting data were plotted, and a calibration factor was obtained from the slope of the resultant line (Simpson, 1970).

\section{Analysis of polycyclic aromatic hydrocarbons}

A Perkin-Elmer Clarus 500 gas chromatograph (GC) with a flame ionisation detector and a $30 \mathrm{~m}$ x $250 \mu \mathrm{m}$ i.d. Perkin Elmer Elite-5HT capillary column (5\% diphenyl, $95 \%$ dimethyl polysiloxane) was used (Aderemi, 2003; Wilcock et al., 1996). Data acquisition and analysis were performed using Perkin-Elmer Turbochrom data acquisition and analysis software. GC operating conditions were: temperature program: hold $3 \mathrm{~min}$ at $70^{\circ} \mathrm{C}$, heat at $12^{\circ} \mathrm{C} / \mathrm{min}$ and hold $6 \mathrm{~min}$ at $330^{\circ} \mathrm{C}$; He carrier gas flow rate: $10.0 \mathrm{ml} / \mathrm{min}$; detector temperature: $250^{\circ} \mathrm{C} ; \mathrm{H}_{2}$ flow rate: $45.0 \mathrm{ml} / \mathrm{min}$; air flow rate: $450 \mathrm{ml} / \mathrm{min}$.

Calibration standards were prepared using concentrations ranging from $10 \mathrm{mg} / \ell$ to $50 \mathrm{mg} / \ell$ for each $\mathrm{PAH}$ of interest through dilution of stock solutions with hexane. The prepared standard solutions for each PAH were chromatographed and peak areas determined. A plot of peak area versus concentration was linear over the concentration range for all components. A stock solution of each standard (anthracene, azulene, dibenzothiophene, fluoranthene, indene and pyrene, abbreviated as ANT, AZU, DIB, FLU, IND, and PYR, respectively) was prepared at a concentration of $1000 \mathrm{mg} / \ell$ in double-distilled hexane and stored in a refrigerator, except for pyrene, which was supplied as a $100 \mathrm{mg} / \ell$ solution. Except for indene and pyrene, the stock solutions were prepared by dissolving $10.0 \mathrm{mg}$ standard in $10 \mathrm{~m} \ell$ double-distilled hexane. Aliquots were taken from the stock solution for dilution to prepare solutions of varying concentrations. For indene (density $0.996 \mathrm{~g} / \mathrm{ml}$ ), $10.4 \mu \ell$ of the liquid was pipetted with an automated micropipette into a $10 \mathrm{~m} \ell$ volumetric flask and topped up with double-distilled hexane to make a $1000 \mathrm{mg} / \ell$ stock standard. Five $\mu \ell$ of each pure standard solution was injected into the GC to determine each compound's retention time. Three replicate injections were made for each PAH standard. Four dilutions of $0.5,1,3$ and $5 \mathrm{mg} / \ell$, respectively, were made in $10 \mathrm{~m} \ell$ flasks and the peak areas were used for plotting calibration curves for all 6 standards.

\section{RESULTS AND DISCUSSION}

\section{Calibration and linearity of the method}

The calibration graphs were linear with correlation coefficients for the linear regression ranging from 0.9302 to 0.9995 . The analytical procedure was tested in terms of sensitivity, recovery and precision of standard mixtures and actual samples. The recoveries of individual PAHs were obtained by standard addition (Table 3). The percentage recovery from water was consistently higher than the percentage recovery from sediment.

\section{TABLE 3}

Retention times and \% recovery of PAH standards

\begin{tabular}{|l|c|c|c|}
\hline Standard & $\begin{array}{c}\text { Retention } \\
\text { time (min) }\end{array}$ & $\begin{array}{c}\text { \% Recovery } \\
\text { from sediment }\end{array}$ & $\begin{array}{c}\text { \% Recovery } \\
\text { from water }\end{array}$ \\
\hline Indene & 5.86 & 74 & 76 \\
\hline Azulene & 9.53 & 61 & 67 \\
\hline Dibenzothiophene & 14.23 & 72 & 74 \\
\hline Anthracene & 14.56 & 77 & 102 \\
\hline Fluoranthene & 17.79 & 60 & 68 \\
\hline Pyrene & 18.62 & 90 & 95 \\
\hline Mean & & 72 & 80 \\
\hline
\end{tabular}

The Instrument Detection Limit (IDL) was determined for each PAH standard (Table 4). The IDL is the analyte concentration required to produce a signal greater than 3 times the standard deviation of the noise level. This was measured by analysing 6 standards at the estimated IDL and then calculating the standard deviation from the measured concentrations of the standards (Miller and Miller, 1984).

\section{Source identification}

PAHs can be used as anthropogenic geochemical tracers and are used to identify the origins of pollutants (Simoneit, 1984; Ding et al., 2007). The ratios of PAHs such as phenanthrene/ anthracene and fluoranthene/(fluoranthene + pyrene) have been used to distinguish different sources in urban and rural areas (Bi et al., 2003; Biache et al., 2014; Cotham and Bidleman, 1995; Lohmann et al., 2000; Motelay-Massei et al., 2007; Ray et al., 2008). In this study fluoranthene/(fluoranthene + pyrene) ratios (Yunker et al., 2002) were calculated for all the samples (Fig. 2). Ratios below 0.5 for individual samples show some correlation with their origin or sampling time, and can be ascribed to episodic petrogenic spillages and grass or wood burning. 


\begin{tabular}{|l|l|c|c|c|}
\hline $\begin{array}{l}\text { TABLE 4 } \\
\text { Instrument Detection Limits (IDL) and regression equations }\end{array}$ \\
\hline Standard & $\begin{array}{c}\text { Detection limit } \\
(\boldsymbol{\mu g} / \boldsymbol{\ell})\end{array}$ & $\begin{array}{c}\text { Linear range } \\
(\mathbf{m g} / \boldsymbol{l})\end{array}$ & $\begin{array}{c}\text { Correlation } \\
\text { coefficient }(\mathbf{r} \mathbf{2})\end{array}$ & Regression equation \\
\hline IND & 83 & $0.5-5$ & 0.9865 & $y=214.49 x+66.47$ \\
\hline Azulene & 4290 & $0.5-5$ & 0.9302 & $y=558.35 x-96.043$ \\
\hline Anthracene & 3180 & $0.5-5$ & 0.9761 & $y=28.797 x+16.757$ \\
\hline Dibenzothiophene & 271 & $0.5-5$ & 0.9930 & $y=219.98 x+199.25$ \\
\hline Fluoranthene & 44 & $0.5-5$ & 0.9892 & $y=84.778 x-64.052$ \\
\hline Pyrene & 46 & $0.05-0.3$ & 0.9957 & $y=42.552 x+2.2014$ \\
\hline
\end{tabular}

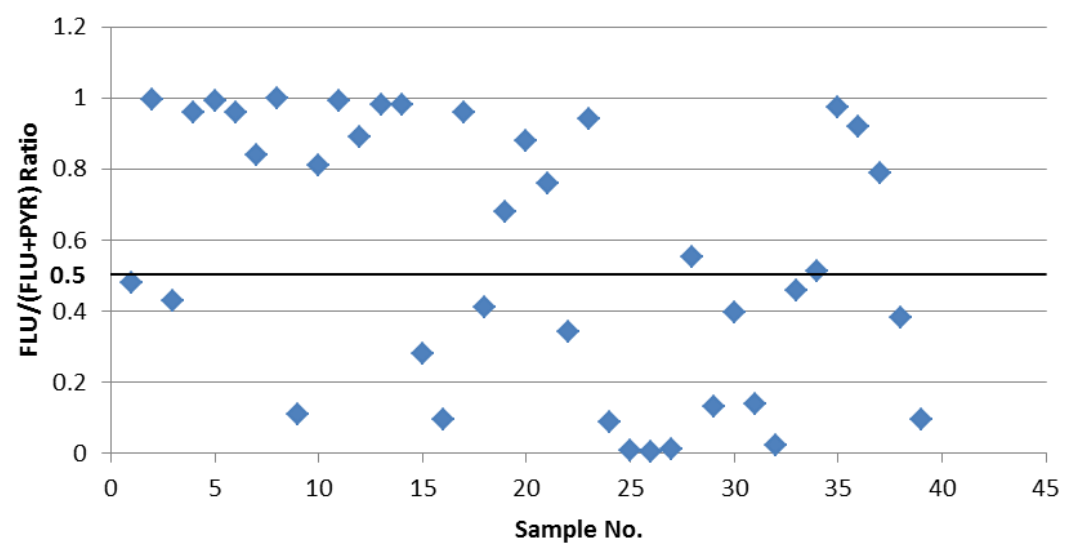

Figure 2

Petrogenic/pyrogenic sources of PAHs in water and sediment samples. FLU/(FLU+PYR) ratios $>0.5$ are characteristic of grass, wood or coal combustion, ratios between 0.4 and 0.5 are characteristic of petroleum combustion, and ratios $<0.4$ indicate petrogenic sources (unburned petroleum).

\section{Estimation of carcinogenic potencies}

Knowing PAH concentrations in the different media allows the estimation of carcinogenic exposure risk to residents of the area. Carcinogenic potencies associated with exposure of a given $\mathrm{PAH}$ can be calculated using benzo[a]pyrene Toxic Equivalency Factors (BaP-TEF) (Tsai et al., 2004; Nisbet and LaGoy, 1992). The TEF is expressed as a ratio of a PAH congener to that of $\mathrm{BaP}$. Adding the product of the concentration of each PAH and its TEF produces a benzo[a]pyrene Toxic Equivalence Quotient (TEQ) for each site. TEFs for the 6 PAHs studied are listed in Table 5, and TEQs in Table 6.

Comparison of these data with standards such as the Dutch soil standards (RIVM, 2001) shows that the TEQ in several sediments far exceeded the Dutch standard. For example, the Dutch standard for anthracene is $17 \mathrm{mg} / \mathrm{kg}$, and for fluoranthene $31 \mathrm{mg} / \mathrm{kg}$.

\section{River water and sediment samples}

The total PAH concentrations in river water samples are shown in Fig. 3 and the total concentrations in sediment samples are shown in Fig. 4. In both series, anthracene was the major individual PAH, reaching levels up to $137 \mu \mathrm{g} / \ell$ in Mutshundudi River water and $9870 \mu \mathrm{g} / \mathrm{kg}$ in Mutshundudi sediment. The total PAH concentration also varied considerably and was higher in sediment samples than in water samples. This is consistent with the high traffic density on roads near this river, with numerous villages, roadside mechanics and carwashes in this catchment alone (own observation). Previously, high total dissolved solids concentrations were found in the Mutshundudi, varying between 5 and $500 \mathrm{mg} / \ell$ (Dederen et al., 2001).

The FLU/(FLU+PYR) ratios (Yunker et al., 2002) indicate the PAHs in the Luvuvhu, Mutshindudi, and Mutale River sites are mostly of pyrogenic origin, whereas the PAHs in the Dzindi

\begin{tabular}{|l|c|}
\hline \multicolumn{2}{|c|}{$\begin{array}{c}\text { TABLE 5 } \\
\text { Toxic Equivalency Factors for the PAHs } \\
\text { in this study (Cal-EPA, 2005) }\end{array}$} \\
\hline PAH & TEF \\
\hline Indene & 0.001 \\
\hline Azulene & 0.0005 \\
\hline Dibenzothiophene & 0.0005 \\
\hline Anthracene & 0.01 \\
\hline Fluoranthene & 0.001 \\
\hline Pyrene & 0.001 \\
\hline
\end{tabular}

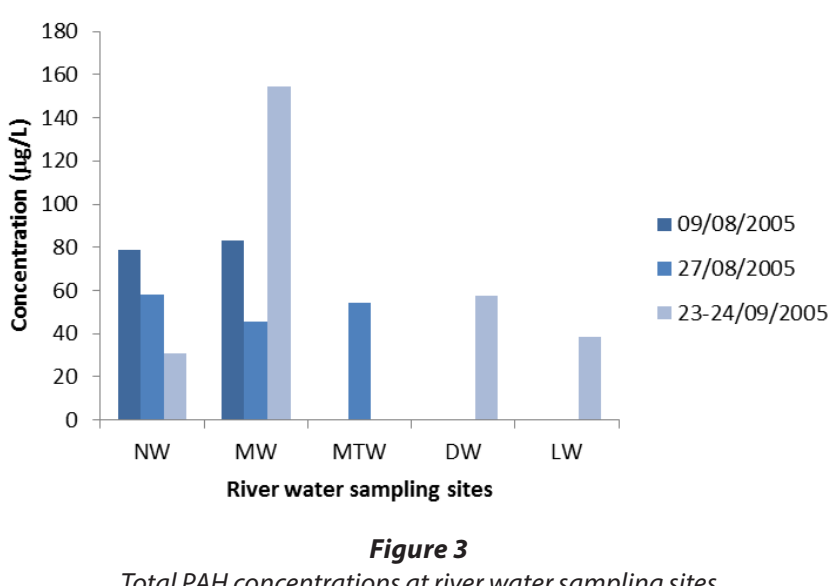

River site are petrogenic. This is in line with car washing and other commercial activities in the vicinity and upstream of the site. All river sediment samples, including those from the Dzindi site, show pyrogenic origins. A European Union directive states a maximum acceptable $\mathrm{PAH}$ value in water of $100 \mathrm{ng} / \ell$ (EU, 2008), but some studies have reported values of $2000-160000 \mu \mathrm{g} / \ell$ in water and $3000 \mu \mathrm{g} / \mathrm{kg}$ in sediment 


\begin{tabular}{|c|c|c|c|c|}
\hline \multicolumn{5}{|c|}{$\begin{array}{l}\text { TABLE } 6 \\
\text { Summary of results. Site Code: (R)W or (R)S after the area code refers to (runoff) water or (runoff) } \\
\text { sediment. }\end{array}$} \\
\hline Site Code & Material & Sampling Point & $\begin{array}{l}\text { Total PAH, } \mu \mathrm{g} / \ell \text { or } \mu \mathrm{g} / \mathrm{kg} \text { : mean } \\
\text { (range) }\end{array}$ & $\begin{array}{l}\mathrm{B}(\mathrm{a}) \mathrm{P} \text { TEQ, } \mu \mathrm{g} / \ell \\
\text { or } \mu \mathrm{g} / \mathrm{kg} \text { : range }\end{array}$ \\
\hline MW & Water & Mutshundudi River & $109.2(29.2-201.5)$ & $0.19-1.43$ \\
\hline MS & Sediment & Mutshundudi River & 11711.6 (8 296-14 044) & $31.60-102.05$ \\
\hline NW & Water & Nzhelele River & $56(31.0-77.9)$ & $0.10-0.67$ \\
\hline NS & Sediment & Nzhelele River & 7035.2 (2 190.3-14 755) & $15.31-97.26$ \\
\hline MTW & Water & Mutale River & 54.6 & 0.34 \\
\hline MTS & Sediment & Mutale River & 5831.1 & 16.34 \\
\hline DW & Water & Dzindi River & 57.7 & 0.36 \\
\hline DS & Sediment & Dzindi River & 2559.2 & 14.76 \\
\hline LW & Water & Luvuvhu River & 38.2 & 0.14 \\
\hline LS & Sediment & Luvuvhu River & 5967.9 & 16.86 \\
\hline MTRW & Runoff water & Mutale Road & $207.6(128.8-286.4)$ & $0.47-2.06$ \\
\hline MTRS & Runoff sediment & Mutale Road & 9502.8 (8 701.5-10 304) & $10.85-12.77$ \\
\hline TPRW & Runoff water & Thohoyandou Parking & $311.4(111.6-511.1)$ & $0.84-2.57$ \\
\hline TPRS & Runoff sediment & Thohoyandou Parking & 22217.7 (9 176.5-35 259) & $0.50-181.51$ \\
\hline UPRW & Runoff water & Univen Parking & 258.6 & 2.00 \\
\hline UPRS & Runoff sediment & Univen Parking & 61764 & 272.23 \\
\hline MRW & Runoff water & Mutshundudi Road & 2553.1 (2 041.4-3064.8) & $2.14-4.03$ \\
\hline MRS & Runoff sediment & Mutshundudi Road & 11355.5 (5 072-17 639) & $20.57-164.28$ \\
\hline NRW & Runoff water & Nzhelele Road & 867.9 (738.7-997) & $0.77-1.14$ \\
\hline NRS & Runoff sediment & Nzhelele Road & 43844.7 (30 176.4-57 513) & $172.26-192.71$ \\
\hline DRW & Runoff water & Dzindi Road & 289.2 & 0.31 \\
\hline DRS & Runoff sediment & Dzindi Road & 111.6 & 100.63 \\
\hline
\end{tabular}

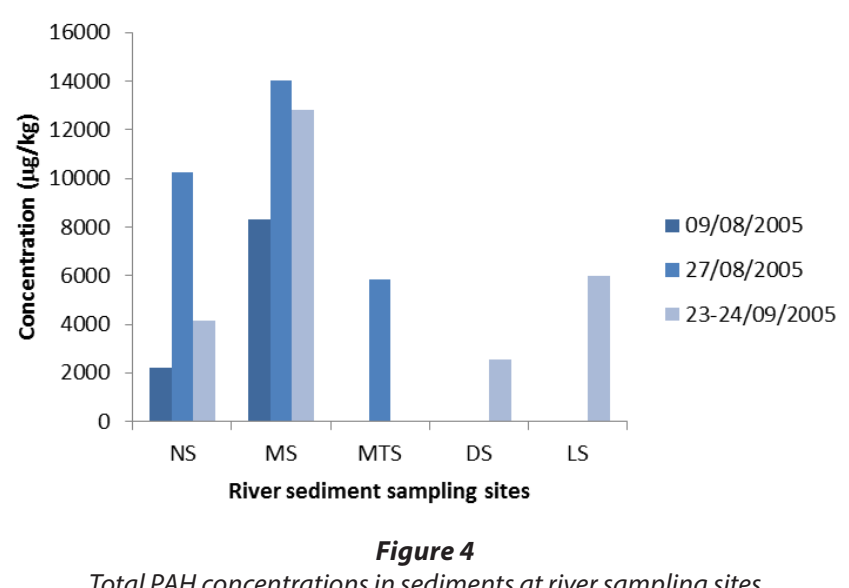

Total PAH concentrations in sediments at river sampling sites

(Vila-Escale et al., 2007). Xu et al. (2007) reported total PAH concentrations ranging between 464000 and $2621000 \mu \mathrm{g} /$ $\mathrm{kg}$ in surface sediment samples of the Yellow River. Canadian sediment quality guidelines (CCME, 2001) are well developed, while development of European guidelines for sediment quality (European Commission, 2010; Carere et al., 2012) has been subject to controversy (Crane, 2003).

Factors contributing to the composition and levels of PAHs in both water and sediment include chemical properties of the compounds, sediment composition, organic carbon and clay content and sedimentary deposition. Sediment with high organic carbon content will generally have high levels of PAHs; sediment with low organic carbon content will have low levels of PAHs (Xu et al., 2007).

Variations in concentration are also influenced by seasonal changes; vapour and particulate phase PAHs tend to be higher in winter than in summer. During the rainy season 'heavy' (higher MW) PAHs dominate in water and sediment (Das et al., 2008), with PAH distribution correlating with particle size (Baek et al., 1991); wind speed also plays an important role in fluctuating of PAH concentrations (Li et al., 2006). Strong winter winds and wild fires, and the number of vehicles on the roads are other variables affecting PAH levels in surface runoff, river water and sediments. Unique air circulation cells over the region are key seasonal factors that could influence deposition and hence PAH concentrations in water and sediment; for example, anticyclonic circulation over the subcontinent in summer results in higher PAH concentrations than in winter, when marine air flows more rapidly into the region, as shown by backward trajectories (Draxler and Rolph, 2003; Hatlane, 2004).

\section{Surface runoff and sediment samples}

The total PAH concentrations in surface runoff samples are shown in Fig. 5 and PAH concentrations in surface sediments in Fig. 6. In these series, anthracene, fluoranthene, and pyrene were major PAHs present, reaching maximum individual concentrations of $23400 \mu \mathrm{g} / \mathrm{kg}$ for anthracene in Univen parking runoff sediment, $12700 \mu \mathrm{g} / \mathrm{kg}$ for fluoranthene in Thohoyandou parking runoff sediment, and $34400 \mu \mathrm{g} / \mathrm{kg}$ for pyrene in Univen parking runoff sediment. FLU/(FLU+PYR) 


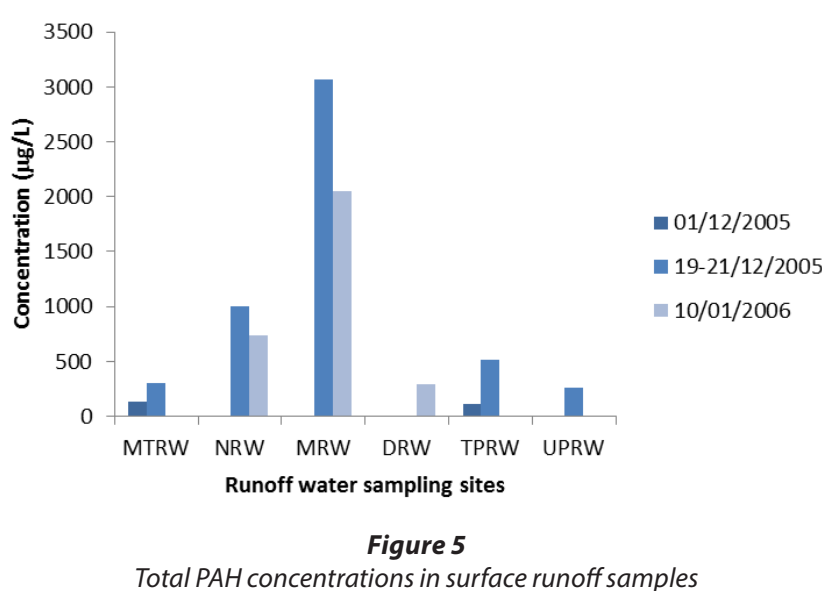

ratios in runoff and sediment samples were generally low, confirming the petrogenic origins of these PAHs.

On the other hand, PAH distribution in surface runoff was dominated by IND, DIB, ANT, FLU and PYR, whereas AZU was undetectable in most of the sediment samples, as well as some of the water samples. The highest individual PAH value in surface runoff water samples was found at the Mutshundudi site (PYR $2500 \mu \mathrm{g} / \ell$ ), followed by the Nzhelele site (PYR 940 $\mu \mathrm{g} / \ell)$. High PAH values in the Mutshundudi and Nzhelele areas might be attributed to traffic density, high rate of indiscriminate refuse dumping and burning of organic refuse. From the results, it is clear that the levels of PAHs in sediment samples are higher than in the water samples.

Urban runoff has been studied extensively by Tsihrintzis and Hamid (1997), who reported that motor vehicle emissions, oil leakage, vehicle tyre wearing and asphalt road surface erosion are common PAH sources in the urban road environment. Li et al. (2006) and Butler et al. (1984) have demonstrated that PAH concentrations in road dust vary according to the distance from the source of pollution. Concentrations of PAHs in UK soils and sediments have been reported ranging between 0.1-54 $\mathrm{mg} / \mathrm{kg}$ (Wild and Jones, 1994), and concentrations between 0.04 and $1.3 \mathrm{mg} / \mathrm{kg}$ have been reported in soils or road dust from remote areas in the USA (ATSDR, 1990). PAH concentrations between 0.01 and $42.58 \mathrm{mg} / \mathrm{kg}$ have been reported in Bahrain soils (Al-Haddad et al., 1993).

\section{Distribution of individual PAHs in river and surface runoff water}

The concentration of each individual PAH in river and surface runoff water is shown in Fig. 7, and the concentrations in river and runoff sediment are shown in Fig. 8. The concentrations of the low-MW PAHs indene, azulene, and anthracene with 2-3 ring structures are generally very low, while the moderate MW 3-4 ring PAHs dibenzothiophene, fluoranthene and pyrene occur in much higher concentrations, especially in sediments. This predominance of pyrogenic PAHs suggests anthropogenic sources such as combustion of fossil fuels and vehicle exhausts. This is confirmed to some extent by the individual fluoranthene/ (fluoranthene + pyrene) ratios calculated for all the samples (Fig. 2).

\section{CONCLUSIONS}

The distribution of PAHs in several samples, especially runoff and sediment collected near commercial areas (Table 6)
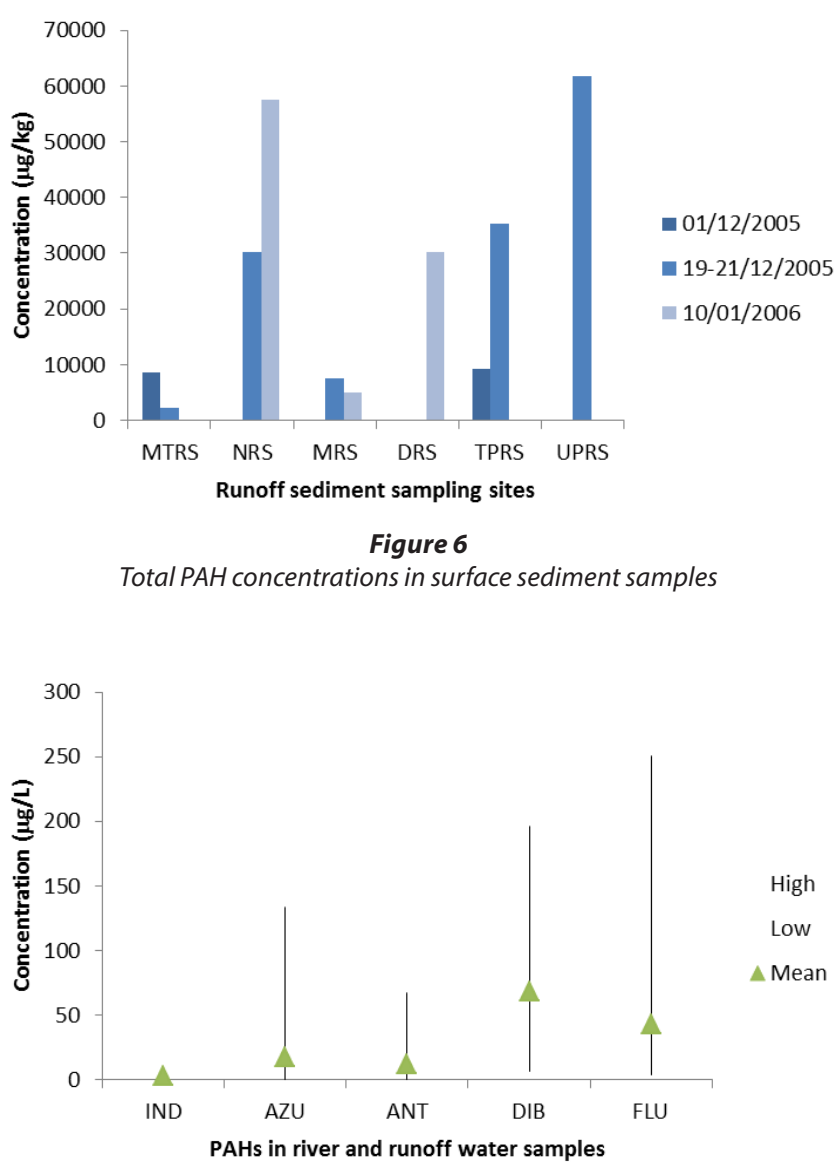

Figure 7

PAH concentrations in river and surface runoff samples. For PYR the values are: high -2500 , low - 0, mean - $335.4 \mu \mathrm{g} / \mathrm{l}$

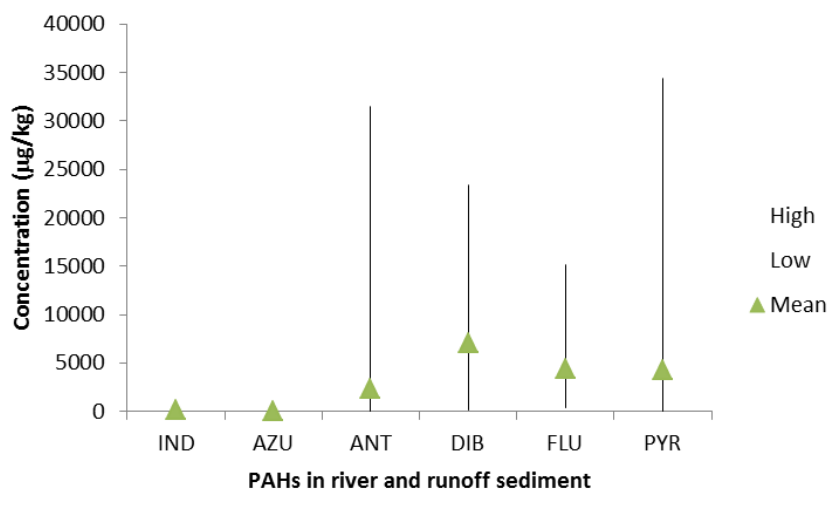

Figure 8

$P A H$ concentrations in river and surface runoff sediment. For IND the values are: high - 179, low - 27.4, mean - $116.0 \mu \mathrm{g} / \mathrm{kg}$, and for AZU: high558 , low-0, mean $-54.1 \mu \mathrm{g} / \mathrm{kg}$.

indicates a potential risk to human health. This impression is confirmed by the TEQ values which in most cases are above acceptable levels. The highest total PAH value was obtained from a Univen parking lot surface runoff sediment sample $(61754 \mu \mathrm{g} / \mathrm{kg})$; the lowest water PAH value $(38.2 \mu \mathrm{g} / \mathrm{kg})$ was obtained from the Luvuvhu River, in a rural area upstream from Thohoyandou. The high values in the University of Venda parking lot and Thohoyandou parking lot are clearly due to the 
large number of motor vehicles that are parked on a daily basis in these places.

PAH values in the Thohoyandou parking lot, which is near a petrol station and a garage, can be attributed to surface wash-off of petrol spillages and oil which is not stored as waste. Samples collected from these areas were very dark, indicating the presence of organic degradation products, of petrogenic origin (Fig. 2). High commercial activity and agricultural production by residents and traders around the Thohoyandou area, which is not adequately monitored by the relevant authorities, might be another cause of these high PAH values.

Runoff values are consistently higher than the values found for waters from the nearest rivers, indicating point sources of PAHs on roads and parking lots, as expected. The low-MW PAHs (2-3 rings) AZU, IND and DIB, were most abundant in water samples, while 4-ringed PAHs (ANT, FLU and PYR) were predominant in sediment samples.

Although there are no large industries around the study area, and no industrial wastes are being discharged directly into the rivers around the study area, municipal sewage waste is discharged directly into some rivers, implicating another probable source of contaminants in rivers. Due to rapid motorisation in recent years, road stormwater runoff can be considered a major source of PAHs. PAH sources in the study area include automobile exhaust, lubricating oils, atmospheric deposition, domestic heating, petrol and diesel engines and organic refuse burning. Since most of the PAH environmental burden is found in the soil (approx. 95\%) (Hassanien and Abdel-Latif, 2008), concentrations of these contaminants in street dust are influenced by traffic density and the rate of atmospheric deposition; hence their concentrations were higher in sediment samples in the present study.

Diesel exhaust, tyres and coated pavements were confirmed to be major contributors of polycyclic aromatic hydrocarbons in road dust in Japan (Pengchai et al., 2005); this study also revealed a significant difference in $\mathrm{PAH}$ profiles between locations and sampling periods. PAHs of anthropogenic origin are formed from either combustion of organic matter or as discharge of petroleum-related materials. Petroleum-derived residues contain high levels of 2-3 ring PAH compounds (Mastral et al., 2003), while high MW PAHs are formed in high-temperature combustion processes (Xu et al., 2007). High levels of PYR and FLU are the result of incomplete combustion, fuel pyrolysis and oil burning (i.e., they have a pyrolytic origin), while ANT and most of the 2-3 ring PAHs have a petrogenic origin ( Feng et al., 2007; Xu et al., 2007).

High PAH concentrations in winter have been reported in many urban atmospheres (Wild and Jones, 1994, Li et al., 2006). Enhanced vehicle exhaust, domestic and space heating, wild fires, long-term dryness and long-range winter winds transporting air pollution over long distances increase the levels of PAHs in winter, in both water and sediments, due to large deposits of particulate PAHs. PAHs then tend to concentrate in rivers and street dust before they can be diluted by good summer rainfalls. This is reflected in the levels of these compounds in the sediment samples. The quality and composition of sediment may be another factor contributing to high PAH levels. Most of the soil in the study area contains clay, which is lipophilic and therefore tends to bind PAHs more strongly. Emission of atmospheric particles from household burning is another possible source; particulate-associated PAHs are transported and deposited into rivers, since the population around the study area is dependent on wood burning for both cooking and space warming in winter.
The fluctuations in PAH concentrations in the present study may indicate the influence of seasonal variation in prevailing atmospheric conditions which favour PAH dispersion and decomposition. Samples were collected between late winter and summer. In Limpopo winters are normally dry and windy with little or no rainfall, whereas summers are very hot, with rainfall, though this is sometimes low, and rainfall is mainly concentrated in late summer.

Variation in concentration may also be further associated with PAH sources and seasonal changes. Low-MW and highMW PAH ratios differ due to seasonal changes. In winter, both low-MW and high-MW PAHs dominate due to cool and dry conditions, whereas in summer the low-MW PAHs easily volatilise from contaminated soil (Gustafson and Dickhut, 1997; Dimashki et al., 2001).

This study shows that the most abundant PAH species are high MW ANT, FLU and PYR, which usually have petrogenic origins and therefore can be attributed to high traffic density, incomplete combustion and the fact that these contaminants are slow to degrade; sediments in particular act as sinks where these chemicals tend to concentrate (Ging et al., 1991). This is consistent with the high PAH values obtained in sediment samples, particularly the runoff sediment samples.

The high abundance of these species appears to be related to motor vehicle emissions, but some studies have demonstrated that enrichment of lower-MW PAHs in roadside dust particles could be attributed to their predominance in large atmospheric particles which deposit faster, in contrast to high-MW ones which predominate in smaller particles and deposit more slowly from the atmosphere (Fang et al., 2004).

The highest $\mathrm{PAH}$ values in sediment samples were for PYR (34 $400 \mu \mathrm{g} / \mathrm{kg})$, followed by ANT (18 $200 \mu \mathrm{g} / \mathrm{kg}$ ) and FLU $(12700 \mu \mathrm{g} / \mathrm{kg})$. Concentrations of PYR and FLU in the road dust of Cairo, Egypt have been recorded as 166 and 68 $\mu \mathrm{g} / \mathrm{kg}$, which was consistent with values obtained in Beijing (Li et al., 2006). PAH levels recorded in the current study are thus considerably higher than those collected in other studies, which may be related to climatic conditions. PAH levels in soil and sediment samples have been reported as, for example, 2 $\mu \mathrm{g} / \mathrm{kg}$ in the United Kingdom, $6.9 \mu \mathrm{g} / \mathrm{kg}$ in Norway, $1.1 \mu \mathrm{g} /$ $\mathrm{kg}$ in Canada and $3.3 \mu \mathrm{g} / \mathrm{kg}$ in Australia (Butler et al., 1984; Jones et al., 1989).

Most PAH levels analysed in the study area were below the maximum allowable concentrations (MAC) in most of the river water samples, but in sediment samples the TEQ values generally exceeded those recommended by the WHO, Canadian, US EPA and Dutch RIVM guidelines (CCME, 2008; US EPA, 1993; RIVM, 2001). On the other hand, the TEQs compare favourably with those for Korean road dust, which ranges from 930 to $16740 \mu \mathrm{g} / \mathrm{kg}$ in industrial areas and from 4370 to 68840 in urban areas (Dong, 2009). In runoff water samples, all of the PAHs were below the MAC, except for pyrene, which does exceed the MAC in some of the samples. In runoff sediment samples, most PAHs do exceed the MAC, and this is consistent with high density of traffic density and other PAH sources.

Although this is a remote rural area, there is considerable traffic between villages and towns, and lively roadside commerce, complicating source identification. The concentrations of PAHs obtained in this study fall within the range of previously reported global and South African data (Das et al., 2008; Nieuwoudt et al., 2011) even though there are some significant differences observed in PAH values, which can be linked back to the contributory sources and origins of the PAHs. Periodic 
monitoring is necessary and urgent to document PAH data in the study area through the development of more sensitive analytical techniques for a greater variety of PAHs.

\section{ACKNOWLEDGEMENT}

The South African National Research Foundation (NRF) is thanked for financial support of this work.

\section{REFERENCES}

ADEREMI OO, ASUBIOJO OI and FATOKI OS (2003) Isolation and determination of polycyclic aromatic hydrocarbons in surface runoff and sediments. Water Air Soil Pollut. 145 245-261.

AL-HADDAD A, MADANY, IM and ABDULLAH FJ (1993) Levels of PCBs and PAHs in Bahrain soil. Environ. Int. 19 (3) 277-284.

ATSDR (AGENCY FOR TOXIC SUBSTANCES AND DISEASE REGISTRY) (2006) Toxicological Profiles CD-ROM. ATSDR, Washington.

ATSDR (AGENCY FOR TOXIC SUBSTANCES AND DISEASE REGISTRY) (1990) Toxicological Profiles for Benzo(a)pyrene. ATSDR, Atlanta.

BAEK SO, GOLDSTONE ME, KIRK PWW, LESTER JN and PERRY R (1991) Phase distribution and particle size dependency of polycyclic aromatic hydrocarbons in the urban atmosphere. Chemosphere 22 (5-6) 503-520.

BI X, SHENG G, PENG PA, CHEN Y, ZHANG Z and FU J (2003) Distribution of particulate- and vapor-phase $n$-alkanes and polycyclic aromatic hydrocarbons in urban atmosphere of Guangzhou, China. Atmos. Environ. 37 289-298.

BIACHE C, MANSUY-HUAULT L and FAURE P (2014) Impact of oxidation and biodegradation on the most commonly used polycyclic aromatic hydrocarbon (PAH) diagnostic ratios: Implications for the source identification. J. Hazard. Mater. 267 31-39.

BUTLER AC and SIBBALD RR (1986) Isolation and gas chromatographic determination of saturated and polycyclic aromatic hydrocarbons in mussels. Bull. Environ. Toxicol. 37 570-578.

BUTLER AC and SIBBALD RR (1987) Sampling and GC-FID, GC/MS analysis of petroleum hydrocarbons in the ocean surface microlayer of Richards Bay, South Africa. Estuar. Coast. Shelf Sci. 25 (1) 27-42.

BUTLER JD, BUTTER VW, KELLOW C and ROBISON HG (1984) Some observations on the polycyclic aromatic hydrocarbons $(\mathrm{PAH})$ content of surface soils in urban areas. Sci. Total Environ. 38 75-85.

CAL-EPA (CALIFORNIA ENVIRONMENTAL PROTECTION AGENCY) (2005) Air Toxic Hot Spots Program Risk Assessment Guidelines, Part II Technical Support Document for Describing Available Cancer Potency Factors. Office of Environmental Health Hazard Assessment, California Environmental Protection Agency, Berkeley, CA.

CARERE M, DULIO V, HANKE G and POLESELLO S (2012) Guidance for sediment and biota monitoring under the Common Implementation Strategy for the Water Framework Directive. Trends Anal. Chem. 36 15-24

CCME (CANADIAN COUNCIL OF MINISTERS OF THE ENVIRONMENT) (1999) Canadian Environmental Quality Guidelines. Canadian Council of Ministers of the Environment, Winnipeg. CCME (CANADIAN COUNCIL OF MINISTERS FOR THE ENVIRONMENT) (2001) Canadian Water Quality Guidelines for the Protection of Aquatic Life: CCME Water Quality Index 1.0. Technical Report, Canadian Council of Ministers of the Environment, Winnipeg, MB, Canada.

CCME (CANADIAN COUNCIL OF MINISTERS FOR THE ENVIRONMENT) (2008) Canadian Soil Quality Guidelines: Carcinogenic and other Polycyclic Aromatic Hydrocarbons (PAHs) (Environmental and Human Health Effects). Scientific Supporting Document. Canadian Council of Ministers of the Environment, Winnipeg, MB, Canada.

COTHAM WE and BIDLEMAN TF (1995) Polycyclic aromatic hydrocarbons and polychlorinated biphenyls in air at an urban and a rural site near Lake Michigan. Environ. Sci. Technol. 29 2782-2789.

CRANE M (2003) Proposed development of Sediment Quality Guidelines under the European Water Framework Directive: a critique. Toxicol. Lett. 142 (3) 195-206.

CRYSTAL D and FOSTER J (1991) Air and Breathing (Datasearch). Hodder and Arnold H\&S, Oxford.

DAS SK, ROUTH J and ROYCHOUDHURY AN (2008) Sources and historic changes in polycyclic aromatic hydrocarbon input in a shallow lake, Zeekoevlei, South Africa. Org. Geochem. 39 (8) 1109-1112.

DEUTSCH-WENZEL RP, BRUNE H, GRIMMER G, DETTBARN G and MISFELD J (1983) Experimental studies in rat lungs on the carcinogenicity and dose-response relationships of eight frequently occurring environmental polycyclic aromatic hydrocarbons. J. Natl. Cancer Inst. 71 539-544.

DIMASHKI M, LIM LH, HARRISON RM and HARRAD S (2001) Temporal trends, temperature dependence and reactivity of atmospheric polycyclic aromatic hydrocarbons. Environ. Sci. Technol. 35 2264-2267.

DING X, WANG XM, XIE ZQ, XIANG CH, MAI BX, SUN LG, ZHENG M, SHENG GY, FU JM and PÖSCHL U (2007) Atmospheric polycyclic aromatic hydrocarbons observed over the North Pacific Ocean and the Arctic area: Spatial distribution and source identification. Atmos. Environ. 41 2061-2072.

DONG TTT and LEE BK (2009) Characteristics, toxicity, and source apportionment of polycylic aromatic hydrocarbons (PAHs) in road dust of Ulsan, Korea. Chemosphere 74 1245-1253.

DRAXLER RR and ROLPH GD (2003) HYSPLIT (Hybrid SingleParticle Lagrangian Integrated Trajectory) Model. NOAA Air Resources Laboratory, Silver Spring, MD.

EL-BEQQALI A, KUSSAK A and ABDEL-REHIM M (2006) Fast and sensitive environmental analysis utilizing microextraction in packed syringe online with gas chromatography-mass spectrometry determination of polycyclic aromatic hydrocarbons in water. $J$. Chromatogr. 1114 234-238.

EUROPEAN COMMISSION (2010) WFD-CIS Guidance Document No. 25. Guidance on chemical monitoring of sediment and biota under the Water Framework Directive. Office for Official Publications of the European Communities, Luxembourg, p. 74 EU (EUROPEAN UNION) (2008) EU Directive 2008/105/EC. Directive 2008/105/EC of the European Parliament and of the Council of 16 December 2008 on environmental quality standards in the field of water policy, amending and subsequently repealing Council Directives 82/176/EEC, 83/513/EEC, 84/156/EEC, 84/491/EEC, 86/280/EEC and amending Directive 2000/60/EC of the European Parliament and of the Council. European Union, Brussels.

FANG GC, CHANG CN, WU YS, FU PP, YANG IL and CHEN MH (2004) Characterization, identification of ambient air and road dust polycyclic aromatic hydrocarbons in Central Taiwan. Sci. Total Environ. 327 135-146.

FENG J, GUO Z, CHAN KC and FANG M (2007) Properties of organic matter - $\mathrm{PM}_{2.5}$ at Changdao Island, China - a rural site in the transport path of the Asian continental outflow. Atmos. Environ. 41 1924-1935.

GHIASVAND AR, HOSSEINZADEH S and PAWLISZYN J (2006) New cold-fiber headspace solid-phase microextraction device for quantitative extraction of polycyclic aromatic hydrocarbons in sediments. J. Chromatogr. 1124 35-42.

GING PB, VANMETRE PC and CALLENDER E (1999) Bottom sediments of Lorence Creek Lake, San Antonio, Texas, reflect contaminant trends in an urbanizing watershed. U.S. Geological Survey Fact Sheet FS-149-99. United States Geological Survey, Reston, Virginia.

GUSTAFSON KE and DICKHUT RM (1997) Particle/gas concentrations and distribution of PAHs in the atmosphere of southern Chesapeake Bay. Environ. Sci. Technol. 31 140-147.

HASSANIEN MA and ABDEL-LATIF NM (2008) Polycyclic aromatic hydrocarbons in road dust over Greater Cairo, Egypt. J. Hazard. Mater. 151 247-254.

HATLANE TN (2004) Aerosol Characteristics at a Background Location. MSc dissertation, University of Venda. 
JONES KC (1993) Polynuclear aromatic hydrocarbons in the United Kingdom environment: a preliminary source and budget. Environ. Pollut. 88 91-108.

JONES KC, STRATFORD JA and TIDRIDGE P (1989) Polynuclear aromatic hydrocarbons in an agricultural soil: long term changes in profile distribution. Environ. Pollut. 56 337-351.

LI X, MA LL, LIU XF, FU S, CHENG HX and XU XBJ (2006) Polycyclic aromatic hydrocarbons in urban soil from Beijing, China. Environ. Sci. 18 944-950.

LOHMANN R, NORTHCOTT GL and JONES KC (2000) Assessing the contribution of diffuse domestic burning as a source of PCDD/Fs, PCBs, and PAHs to the U.K. atmosphere. Environ. Sci. Technol. 34 2892-2899.

LOOKING4SPARES (2014). URL: http://www.looking4spares.co.za/ directory/scrap-yards-/limpopo/scrap-yards--thohoyandou--scrapyards--limpopo (Accessed 9 March 2014).

MAHBUB P, AYOKO G, GOONETILLEKE A, EGODAWATTA P and KOKOT S (2010) Impacts of traffic and rainfall characteristics on heavy metals build-up and wash-off from urban roads. Environ. Sci. Technol. 44 (23) 8904-8910.

MALDONADO C, BAYONA J and BODINEAU L (1999) Sources, distribution and water column process of aliphatic and polycyclic aromatic hydrocarbons in the northwestern Black Sea water. Environ. Sci. Technol. 33 2693-2702.

MASTRAL AM, LOPÉZ JM, CALLÉN MS, GARCÍA T, MURILLO R and NAVARRO MV (2003) Spatial and temporal PAH concentrations in Zaragoza, Spain. Sci. Total Environ. 307 (1-3) 111-124.

MILLER JC and MILLER JN (1984) Statistics for Analytical Chemistry. Ellis Horwood, Chichester. 119 pp.

MOJA SJ, MTUNZI F and MADLANGA X (2013) Determination of polycyclic aromatic hydrocarbons (PAHs) in river water samples from the Vaal Triangle area in South Africa. J. Environ. Sci. Health A: Tox. Hazard. Subst. Environ. Eng. 48 (8) 847-854.

MOTELAY-MASSEI A, OLLIVON D, GARBAN B, TIPHAGNELARCHER K, ZIMMERLIN I and CHEVREUIL M (2007) PAHs in the bulk atmospheric deposition of the Seine river basin: Source identification and apportionment by ratios, multivariate statistical techniques and scanning electron microscopy. Chemosphere 67 312-321.

NISBET C and LAGOY P (1992) Toxic equivalency factors (TEFs) for polycyclic aromatic hydrocarbons (PAHs). Regul. Toxicol. Pharmacol. 16 290-300.

NIEUWOUDT C, PIETERS R, QUINN LP, KYLIN H, BORGEN AR and BOUWMAN H (2011) Polycyclic aromatic hydrocarbons (PAHs) in soil and sediment from industrial, residential, and agricultural areas in central South Africa: An initial assessment. Soil Sediment Contam. 20 (2) 188-204.

OGUNFOWOKAN AO, ASUBIOJO OI and FATOKI OS (2003) Isolation and determination of polycyclic aromatic hydrocarbons in surface runoff and sediments. Water Air Soil Pollut. 145 245-261.

PASSIVIRTA J (1991) Chemical Ecotoxicology. Lewis Publishers (CRC Press), Boca Raton.

PENGCHAI P, NAKAJIMA F and FURUMAI H (2005) Estimation of origins of polycyclic aromatic hydrocarbons in size-fractionated road dust in Tokyo with multivariate analysis. Water Sci. Technol. 51 169-175.

RAY S, KHILLARE PS, AGARWAL T and SHRIDHAR V (2008) Assessment of PAHs in soil around the International Airport in Delhi, India. J. Hazard. Mater. 156 9-16.

REZAEE M, ASSADI Y, HOSSEIN MM, AGHEE E, AHMADI M and BERIJINI S (2006) Determination of organic compounds in water using dispersive liquid-liquid microextraction. J. Chromatogr. 1116 $1-9$.

RIVM (RIJKSINSTITUUT VOOR VOLKSGEZONDHEID EN MILIEU) (2001) Re-evaluation of human-toxicological maximum permissable risk levels. RIVM report 711701025 . RIVM, Bilthoven.
SAUER T and BOEHM P (1991) The use of defensible analytical chemical measurements for oil spill. Natural Resource Damage Assessment Proceedings, 1991 Oil Spill Conference. 363-369.

SIMONEIT BRT (1984) Organic matter of the troposphere III. Characterization and sources of petroleum and pyrogenic residues in aerosols over the western United States. Atmos. Environ. 36 51-67.

SIMPSON C (1970) Gas Chromatography. Kogan Page, Cambridge. 80 pp. TSAI PJ, SHIH TS, CHEN HL, LEE WJ, LAI CH AND LIOU SH (2004) Assessing and predicting the exposures of polycyclic aromatic hydrocarbons (PAHs) and their carcinogenic potencies from vehicle engine exhausts to highway toll station workers. Atmos. Environ. 38 333-343.

TSIHRINTZIS VA and HAMID R (1997) Modeling and management of urban stormwater runoff quality: a review. Water Resour. Manag. 11 137-164.

US EPA (UNITED STATES ENVIRONMENTAL PROTECTION AGENCY) (1993) Provisional Guidance for Quantitative Risk Assessment of Polycyclic Aromatic Hydrocarbons, EPA/600/R93/089. Environmental Protection Agency, Washington, DC.

US EPA (UNITED STATES ENVIRONMENTAL PROTECTION AGENCY) (1996) US EPA Method 3540C Rev. 3. Soxhlet Extraction. Environmental Protection Agency, Washington, DC.

US EPA (UNITED STATES ENVIRONMENTAL PROTECTION AGENCY) (2007) US EPA Method 8330 Rev. 1. Nitroaromatics and Nitramines by High Performance Liquid Chromatography (HPLC). Test Methods for Evaluating Solid Waste, 1. Office of Solid Waste, Washington, DC.

DEDEREN JJ, FOUCHE PSO, GAIGHER IG, GAIGHER MJ, JOHN RP, LIGAVHA M, MASHAU E, MENNE PF, NETHONONDA LO, SZUBARGA A, TODD C, VAN DER WAAL BCW, VAN REE T, VENTER C, WOOD C and WEISSER P (2001) A Socio-Biological Study of the Aquatic Resources and their Utilization in an Underdeveloped Rural Region, the Mutshindudi River Catchment. WRC Report No. 714/2/01. Water Research Commission, Pretoria.

VILA-ESCALE M, VEGAS-VILARRUBIA T and PRAT N (2007) Release of polycyclic aromatic compounds into a Mediterranean creek (Catalonia, NE Spain) after a forest fire. Water Res. 41 2171-2179.

WANG Z and FINGAS M (1995) Use of methyldibenzothiophenes as markers for differentiation and source identification of crude and weathered oils. Environ. Sci. Technol. 29 (11) 2842-2849.

WILCOCK RJ, CORBAN GA, NORTHCOTT GL, WILKINS A and LANGDON AG (1996) Persistence of polycyclic aromatic hydrocarbons of different molecular size and water solubility in surficial sediments of an intertidal sandflat. Environ. Toxicol. Chem. 15 670-676.

WILD SR and JONES KC (1994) Polynuclear aromatic hydrocarbons in the United Kingdom environment: A preliminary source inventory and budget. Environ. Pollut. 88 91-108.

ANGLISS M, ASHTON P, COOK C, DEACON A, FOORD S, FOUCHÉ P, HENNING D, KLEYNHANS N, RODGERS S, ROUX D, STRYDOM W, VINK D, VAN DER WAAL BCW, VAN WYK E and VLOK W (2001) State of River Report: Letaba and Luvuvhu river system. WRC Report No. TT165/01. Water Research Commission, Pretoria.

XU J, YU Y, WANG P, GUO W, DAI S and SUN H (2007) Polycyclic aromatic hydrocarbons in surface sediment from Yellow River, China. Chemosphere 67 1408-1414.

YUNKER MB, MACDONALD RW, VINGARZAN R, MITCHELL RH, GOYETTE D and SYLVESTRE S (2002) PAHs in the Fraser River Basin: a critical appraisal of PAH ratios as indicators of PAH source and composition. Environ. Pollut. 33 489-515.

ZENG EY, TRAN K and YOUNG D (2004) Evaluation of potential molecular markers for urban stormwater runoff. Environ. Monit. Assess. $9023-43$. 